\title{
COMUNICAÇÃ̃O
}

\section{PROPAGAÇÃO DE FIGUEIRA (Ficus carica L.) POR MEIO DE ESTACAS RETIRADAS DURANTE O PERÍODO VEGETATIVO}

\author{
Propagation of fig tree (Ficus carica L.) by cuttings obtained during vegetative period
}

\author{
Ângela Maria Nogueira ${ }^{1}$, Nilton Nagib Jorge Chalfun ${ }^{2}$, \\ Leonardo Ferreira Dutra ${ }^{3}$, Fabíola Villa ${ }^{4}$
}

\begin{abstract}
RESUMO
Na obtenção de mudas de figueira (Ficus carica L.) de raiz nua por meio de estacas lenhosas, além de demandar em torno de um ano para sua obtenção, ocorre alto percentual de perda, requerendo grande quantidade de material vegetal. Com o uso de estacas herbáceas, objetivou-se verificar o seu enraizamento influenciado pela presença e ausência das folhas, coletadas de plantas-matrizes com e sem frutos e tratadas com AIB em diferentes concentrações. As estacas herbáceas foram retiradas da porção mediana de ramos de figueira 'Roxo de Valinhos' preparadas com $25 \mathrm{~cm}$ de comprimento e $15 \mathrm{~mm}$ de diâmetro aproximadamente e foram imersas em solução de AIB nas concentrações de 0,150 e $300 \mathrm{mg} \mathrm{L}^{-1}$ durante 24 horas. Posteriormente, foram plantadas em sacolas de polietileno preto contendo areia lavada e solo em mistura na proporção de 3:2 v/v como substrato e mantidas em casa-de-vegetação sob nebulização intermitente durante 60 dias. Maiores percentuais de enraizamento, peso da matéria seca das brotações e das raízes foram obtidas em estacas sem folhas e coletadas de plantas-matrizes sem frutos. Constatou-se ainda que não houve necessidade do tratamento das estacas com AIB.
\end{abstract}

Termos para indexação: Figo, estaquia, enraizamento, regulador de crescimento.

\begin{abstract}
Roots from young fig plants (Ficus carica L.) obtained through hardwood cuttings takes around one year and it has a high percentage of loss a large requesting amount of propagation material. With the use of herbaceous cuttings, it was aimed to verify its rooting influence by the presence and absence of leaves, collected from mother-plants with fruits, without fruits and treated with indolbutyric acid in different concentrations. The herbaceous cuttings were removed from the middle portion of fig branches cv. Roxo de Valinhos with $15 \mathrm{~cm}$ length and $15 \mathrm{~mm}$ diameter approximately and they were clipped in indolbutyric acid solution on 0,150 and $300 \mathrm{mg} \mathrm{L}^{-1}$ concentrations during 24 hours. After this period, the cuttings were planted in black polyethylene bags containing washed sand and soil mixture inside $(3: 2 \mathrm{v} / \mathrm{v})$ as a substrate and maintained in greenhouse under intermittent mist for 60 days. Higher percentage of rooting, dry matter weight of sprouts and roots dry matter weight of roots were obtained in cuttings without leaves and collected from mother-plants without fruits. It is not necessary the treatment with indolbutyric acid in cuttings.
\end{abstract}

Index terms: Fig, cuttings, rooting, growth regulator.

(Recebido em 26 de janeiro de 2005 e aprovado em 16 de fevereiro de 2006)

A propagação de figueira por meio de estacas lenhosas é o processo de multiplicação mais utilizado no Brasil (ALMEIDA \& SILVEIRA, 1997; SILVA, 1983). Segmentos destacados da planta-mãe colocados sob condições adequadas formam raízes adventícias, originando uma nova planta idêntica àquela que lhe deu origem (VALIO, 1986). A utilização de estacas lenhosas é justificada por permitir o uso do material descartado por ocasião da poda hibernal, preferencialmente ramos de um ano de idade, e o enraizamento sem estruturas especiais de nebulização (CHALFUN et al., 2002), permitindo a formação de mudas diretamente no viveiro (ARRUDA NETO, 1971; PINHEIRO \& OLIVEIRA, 1973).

Entretanto, a obtenção de mudas de raiz nuas por meio de estacas lenhosas demanda em torno de um ano, visto que as estacas obtidas e postas a enraizar no inverno, somente serão transplantadas para o local definitivo no inverno do ano seguinte. Por outro lado, se postas a enraizar diretamente no campo, tem-se verificado muitas falhas no pegamento, devido à falta de umidade no solo. Para compensar tais falhas, recomenda-se o uso de duas estacas por cova (CHALFUN \& HOFFMANN,

\footnotetext{
'Engenheira Agrônoma, Doutora em Fitotecnia pelo Departamento de Agricultura/DAG da Universidade Federal de Lavras/UFLA - Cx. P. 3037 37200-000 - Lavras, MG - fardim02@yahoo.com.br

'Engenheiro Agrônomo, Dr., Professor Adjunto do Departamento de Agricultura/DAG da Universidade Federal de Lavras/UFLA UFLA - Cx. P. 3037 37200-000 -Lavras, MG - nchalfun@ufla.br

${ }^{3}$ Engenheiro Agrônomo, Dr., Pesquisador do CNPF/EMBRAPA - Cx. P. 319 - 83411-000 - Colombo, PR - leo@cnpf.embrapa.br

${ }^{4}$ Engenheira Agrônoma, Doutoranda em Fitotecnia no Departamento de Agricultura/DAG da Universidade Federal de Lavras/UFLA - Cx. P. 3037 Lavras, MG - fvilla2003@libero.it
} 
1997), o que acarreta a utilização de grande quantidade de material propagativo.

Com a introdução de um novo sistema de condução da figueira por meio de desponte, na obtenção de figos, ocorrem perdas significativas de material propagativo. Assim, torna-se importante estudar a possibilidade de enraizamento desse material herbáceo descartado, o que decorre em vantagem, proporcionando já no inverno seguinte, doze meses após, a obtenção de mudas enraizadas e prontas para comercialização (CHALFUN \& HOFFMANN, 1997).

O uso de estacas semilenhosas de figueira 'Roxo de Valinhos', sob nebulização intermitente, permitiu a obtenção de percentuais de enraizamento de $100 \%$ em estacas com folhas tratadas com ácido indolbutírico a 800 $\mathrm{mg} \mathrm{L}^{-1}$ (NUNES, 1981).

A utilização de estacas herbáceas de figueira 'Roxo de Valinhos' com meristema apical, sob nebulização intermitente, permitiram a obtenção de maior enraizamento e dispensou a aplicação de reguladores de crescimento, obtendo-se praticamente $100 \%$ das estacas enraizadas após 32 dias (KERSTEN \& FACHINELLO, 1981).

Embora tenham sido obtidos resultados promissores com estacas herbáceas e semilenhosas na propagação da figueira, não se recomenda o seu uso na propagação comercial de mudas, visto que as plantasmatrizes estão em produção (CHALFUN \& HOFFMANN, 1997). Em contrapartida, justificam a sua utilização em casos de pouca disponibilidade de material propagativo ou se deseje modificar a época de produção das mudas.

A utilização de reguladores de crescimento é indicada com o objetivo de acelerar a formação de raízes, aumentar o percentual de enraizamento das estacas, promover a melhoria da qualidade das raízes e aumentar a uniformidade no viveiro (ALBUQUERQUE \& ALBUQUERQUE, 1981). Dentre os grupos de reguladores de crescimento utilizados, as auxinas desempenham papel importante. $\mathrm{O}$ ácido indolbutírico (AIB) é a auxina sintética mais utilizada e mais eficiente para promover o enraizamento de estacas, sendo efetivo para um grande número de plantas (BOSE \& MANDAL, 1972).

Devido à facilidade de enraizamento das estacas de figueira, o uso de reguladores de crescimento é dispensável (CHALFUN \& HOFFMANN, 1997). Antunes et al. (1996), em trabalho com estacas da cultivar Roxo de Valinhos, não obtiveram efeito significativo do uso de AIB. Semelhante resultado foi constatado com estacas de figueira
'Adriatic', 'Kodota', 'Mission' e 'Calimyrna' (CRANE \& MALLAH, 1952).

Entretanto, vários trabalhos constataram o efeito benéfico da aplicação de reguladores de crescimento no enraizamento de estacas de figueira (ALBUQUERQUE \& ALBUQUERQUE, 1981; KERSTEN \& FACHINELLO, 1981; NUNES, 1981).

Como produtores de assimilados e de outras substâncias para o enraizamento, as folhas presentes nas estacas têm um papel chave na formação de raízes. Em experimentos com oliveira (Olea europaea L.), constatouse que as folhas são imprescindíveis para a iniciação radicular (CABALLERO \& NAHLAWI, 1979; FONTANAZZA \& RUGINI, 1977). Há a necessidade de um equilíbrio entre auxinas e hidratos de carbono para a produção de raízes, já que durante o processo de enraizamento ocorrem contínuas perdas de amido e açúcares solúveis na base das estacas, que é um forte dreno de assimilados (DAVIES, 1983).

A utilização de estacas provenientes de árvores em produção diminui o percentual de enraizamento pela baixa disponibilidade de hidratos de carbono (DEL-RIO \& CABALLERO, 1991). Durante o período de enraizamento de estacas com frutos, estabelece-se entre estes e a base das estacas uma competição por assimilados, ocasionando um empobrecimento em hidratos de carbono, que reduz sua capacidade de enraizar (RALLO \& DEL-RIO, 1990).

As plantas fornecedoras de estacas herbáceas durante a primavera/verão, além de possuírem folhas, se encontram com frutos. Desta forma, há a necessidade de avaliar o comportamento de plantas matrizes que estão em fase vegetativa/reprodutiva, em relação ao enraizamento de estacas, pois o fruto é considerado um dreno, podendo assim retirar reservas que podem ajudar no enraizamento. Assim, o presente trabalho, teve como objetivo verificar a influência de diferentes concentrações de AIB no enraizamento de estacas de figueira com e sem folhas, provenientes de plantas com e sem frutos.

Estacas herbáceas da porção mediana do ramo, preparadas com comprimento de $25 \mathrm{~cm}$, diâmetro médio de $15 \mathrm{~mm}$, aproximadamente, com corte horizontal na base e em bisel na extremidade superior, foram coletadas de plantas de figueira (Ficus carica L.) 'Roxo de Valinhos', com 8 anos de idade, sadias e uniformes, conduzidas no pomar da Fazenda Experimental da EPAMIG, em Caldas, MG. Estas foram acondicionadas em feixes e envoltas em jornal úmido e em seguida transportadas até a UFLA, em Lavras. 
Os tratamentos consistiram de estacas preparadas com ou sem folhas, coletadas de plantas com ou sem frutos e tratadas com solução de ácido indolbutírico (AIB) nas concentrações de 0,150 e $300 \mathrm{mg} \mathrm{L}^{-1}$, imergindo $5 \mathrm{~cm}$ da sua base durante 24 horas seguido de imersão em solução fungicida Captan 2,5\%. O preparo das soluções de AIB foi realizado no Laboratório de Cultura de Tecidos Vegetais. Dissolveu-se o AIB previamente calculado e pesado em balança de alta precisão, adicionando-se, posteriormente, dez gotas de hidróxido de sódio $(\mathrm{NaOH}$ $0,5 \mathrm{~N})$. Depois de tratadas, as estacas foram acondicionadas em sacolas de polietileno preto, com dimensões de 18 x $30 \mathrm{~cm}$ contendo uma mistura de areia lavada e solo de textura arenosa na proporção de 3:2 v/v como substrato e mantidas em casa-de-vegetação, sob nebulização intermitente.

O experimento foi conduzido em delineamento inteiramente casualizado, com 4 repetições de 20 estacas cada, seguindo um fatorial $2 \times 2 \times 3$, onde o fator folha foi representado por dois níveis (estacas com e sem), o fator fruto também por dois níveis (plantas com e sem) e o fator AIB por três níveis $\left(0,150\right.$ e $\left.300 \mathrm{mg} \mathrm{L}^{-1}\right)$. Decorrido o período de 60 dias, avaliou-se a porcentagem de estacas enraizadas e o peso da matéria seca da parte aérea e das raízes.

Maiores percentuais de enraizamento foram obtidos em estacas desprovidas de folhas em relação àquelas enfolhadas (Tabela 1). Somente não houve diferença entre as estacas, com relação à presença ou ausência de folhas, quando estas não foram tratadas com AIB.
O tratamento com AIB das estacas sem folhas não foi efetivo, com pequena tendência a decrescer, enquanto que nas estacas enfolhadas, reduziu o percentual de estacas enraizadas.

A constatação de que não há diferença no percentual de enraizamento entre estacas com ou sem folhas, não tratadas com AIB, é importante na medida em que a propagação da figueira por estacas herbáceas sem folhas pode dispensar o uso da nebulização, uma vez que a prevenção do murchamento é especialmente importante nos casos em que são utilizadas estacas com folhas (FACHINELLO et al., 1995).

A utilização de estacas de figueira obtidas de plantas sem frutos permitiu a obtenção de maiores percentuais de enraizamento (Tabela 1). Em relação ao tratamento com regulador de crescimento, a maior porcentagem de estacas enraizadas foi obtida quando as estacas, oriundas tanto de plantas com frutos quanto de plantas sem fruto, não foram tratadas com AIB. Houve maior redução no percentual de enraizamento em estacas obtidas de plantas com frutos do que nas obtidas de plantas sem frutos, com o aumento das concentrações do regulador de crescimento.

No entanto, há que se considerar que a diferença no percentual de enraizamento entre estacas coletadas de plantas com e sem frutos foi de apenas $11 \%$, sem a aplicação de AIB. Nesse sentido, pode-se sugerir a utilização de estacas herbáceas provenientes de plantas-matrizes mesmo que estejam em produção, possibilitando a antecipação da produção de mudas.

TABELA 1 - Porcentagem de enraizamento de estacas de figueira, com ou sem folhas, retiradas com ou sem frutos, tratadas com ácido indolbutírico.

\begin{tabular}{lccc}
\hline Tipo de estaca & \multicolumn{3}{c}{ Estacas enraizadas (\%) } \\
\hline & 0 & Ácido indolbutírico $\left(\mathrm{mg} \mathrm{L}^{-1}\right)$ \\
\cline { 2 - 4 } & $72,29 \mathrm{aA}$ & 150 & 300 \\
\hline Sem folha & $71,54 \mathrm{aA}$ & $72,26 \mathrm{aA}$ & $60,32 \mathrm{aA}$ \\
Com folha & \multicolumn{3}{c}{$22,50 \mathrm{bB}$} \\
\hline \multicolumn{3}{c}{0} & Ácido indolbutírico $\left(\mathrm{mg} \mathrm{L}^{-1}\right)$ \\
\hline & 0 & 150 & 300 \\
\hline Sem fruto & $77,46 \mathrm{aA}$ & $67,39 \mathrm{aAB}$ & $59,57 \mathrm{aB}$ \\
\hline Com fruto & $66,37 \mathrm{bA}$ & $29,57 \mathrm{bB}$ & $23,25 \mathrm{bB}$ \\
\hline
\end{tabular}

Médias seguidas por letras distintas, minúsculas na vertical e maiúsculas na horizontal, diferem entre si pelo teste de Tukey a $5 \%$ de probabilidade.

Ciênc. agrotec., Lavras, v. 31, n. 3, p. 914-920, maio/jun., 2007 
Analisando os dados referentes ao peso da matéria seca das brotações, verifica-se que as estacas desprovidas de folhas apresentam os maiores pesos quando tratadas com AIB em relação às com folhas (Tabela 2). Quando estas não foram tratadas com AIB, não houve diferença estatística entre as mesmas, em relação à presença ou ausência de folhas. A aplicação de AIB em estacas sem folhas não foi efetiva, enquanto que nas estacas enfolhadas promoveu redução no peso da matéria seca das brotações.

Maiores pesos da matéria seca das brotações foram obtidos em estacas oriundas de plantas sem frutos quando tratadas com AIB (Tabela 2). Nas estacas que não foram tratadas, não se verificou diferença estatística entre a presença ou não de frutos nas plantas matrizes. O tratamento das estacas provindas de plantas sem frutos propiciou maiores pesos da matéria seca das brotações com a aplicação de $150 \mathrm{mg} \mathrm{L}^{-1}$ de AIB, diferindo estatisticamente somente da concentração de $300 \mathrm{mg} \mathrm{L}^{-1}$. Quando as estacas foram obtidas de plantas com frutos, o maior peso da matéria seca das brotações foi obtido na ausência de AIB, reduzindo com o aumento das concentrações desse regulador de crescimento.

Quanto ao peso da matéria seca das raízes (Tabela 3), constatou-se que a utilização de estacas sem folhas permite a obtenção de maiores pesos, quando tratadas com AIB. Entretanto, quando as estacas não foram tratadas com AIB, não houve diferença estatística entre as estacas com ou sem folhas. Com o tratamento com AIB, o maior peso da matéria seca das raízes foi obtido com $150 \mathrm{mg} \mathrm{L}^{-1}$ de AIB, que não diferiu estatisticamente quando se omitiu o tratamento (dose 0). Em estacas com folhas, a ausência de AIB promoveu o maior peso, decrescendo com o aumento das concentrações do AIB.

Maiores pesos da matéria seca das raízes foram obtidos em estacas retiradas de plantas sem frutos (Tabela 3 ). No entanto, quando as estacas não foram tratadas com AIB, não se verificaram diferenças estatísticas entre as estacas oriundas de plantas com ou sem frutos.

O maior peso da matéria seca das raízes foi obtido com $150 \mathrm{mg} \mathrm{L}^{-1}$ de AIB em estacas provindas de plantas sem frutos, diferindo estatisticamente somente da concentração de $300 \mathrm{mg} \mathrm{L}^{-1}$, enquanto que em estacas de plantas com frutos, o melhor resultado foi obtido na ausência de AIB. Norberto (1999) verificou que, na concentração de $100 \mathrm{mg} \mathrm{L}^{-1}$ é eficiente para estimular o enraizamento, bem como aumentar o peso da matéria seca tanto das raízes quanto da parte aérea. Pio (2002) observou que, a ausência de AIB favoreceu o alongamento da maior raiz da estaca e maiores concentrações promoveram o aumento da biomassa seca das raízes.

Os maiores percentuais de enraizamento, pesos da matéria seca das brotações e das raízes obtidos em estacas de figueira sem folhas, independentemente da concentração de AIB utilizada, podem ser devidos, provavelmente, a um alto conteúdo endógeno de auxina nas estacas, visto que as plantas-matrizes se encontravam em pleno período vegetativo. Essa suposição é corroborada pelos fatos de que não houve diferença entre estacas com ou sem folhas quando estas não foram tratadas com AIB e o decréscimo ocasionado pelo tratamento das estacas enfolhadas com AIB. O efeito inibitório causado pela aplicação de ácido indolbutírico em estacas com folhas possivelmente pode ter sido causado por um efeito fitotóxico em função de um alto teor endógeno de auxina, sintetizada pelas folhas, aliado à aplicação exógena de ácido indolbutírico. $\mathrm{O}$ aumento da concentração de auxina exógena aplicada em estacas provoca efeito estimulador de raízes até um valor máximo, a partir do qual qualquer acréscimo de auxinas tem efeito inibitório (FACHINELLO et al., 1995). O teor adequado de auxina exógena para estímulo do enraizamento depende da espécie e da concentração de auxina existente no tecido. Meristemas de brotos apicais, folhas jovens e folhas maduras (em menor quantidade) são sítios primários de síntese de AIA (ácido indolacético) (TAIZ \& ZEIGER, 1998). O conteúdo de AIA na base de estacas de Pinus sylvestris L. tratadas com AIB foi três vezes maior do que nas não tratadas (DUNBERG et al., 1981). Como não foram observadas diferenças no metabolismo ou transporte de AIA entre as estacas tratadas e não tratadas, os autores concluíram que o AIB aplicado foi convertido para AIA pelas estacas.

A inexistência de diferença no percentual de enraizamento de estacas de figueira com e sem folhas quando não tratadas com AIB, sugere que não há a necessidade da aplicação de reguladores de crescimento em estacas dessa espécie. Em trabalho com a cultivar 'Roxo de Valinhos', não foi constatado efeito significativo do AIB aplicado nas estacas de inverno (ANTUNES et al., 1996).

Os maiores percentuais de enraizamento, pesos da matéria seca das brotações e das raízes obtidos em estacas retiradas de plantas sem frutos apresentam a mesma tendência dos resultados obtidos com estacas sem folhas. Esse fato pode ter ocorrido provavelmente em função dos frutos jovens também serem fontes de auxinas e, dessa forma, estacas obtidas de plantas doadoras com frutos, possuem alto teor endógeno desse hormônio, o que aliado 
à aplicação exógena de AIB, ocasionou efeito fitotóxico nas estacas. Frutos em desenvolvimento também são sítios de síntese de AIA (TAIZ \& ZEIGER, 1998).

Já o menor percentual de enraizamento de estacas retiradas de plantas com frutos pode ser devido não só ao efeito fitotóxico, provavelmente em função de um alto teor endógeno de auxina produzida pelos próprios frutos, mas também ao menor conteúdo de carboidratos nas estacas, em função desses estarem sendo carreados para os frutos. A utilização de estacas provenientes de árvores em produção diminui muito o percentual de enraizamento, em função da baixa disponibilidade de hidratos de carbono (DEL-RIO \& CABALLERO, 1991). Durante o período de enraizamento de estacas com frutos, estabelece-se entre estes e a base das estacas uma competição por assimilados, ocasionando um empobrecimento em hidratos de carbono, que reduz sua capacidade de enraizar (RALLO \& DELRIO, 1990). A importância dos carboidratos refere-se ao fato de que a auxina requer uma fonte de carbono para a biossíntese dos ácidos nucleicos e proteínas, e leva à necessidade de energia e carbono para a formação de raízes (FACHINELLO et al., 1995).

Maiores percentuais de enraizamento, peso da matéria seca das brotações e das raízes são obtidos em estacas sem folhas e coletadas sem frutos;

Não há a necessidade do tratamento das estacas de figueira com/sem folhas e com/sem frutos coletadas no período vegetativo com ácido indolbutírico.

TABELA 2 - Peso da matéria seca das brotações de estacas de figueira, com ou sem folhas, retiradas com ou sem frutos, tratadas com ácido indolbutírico.

\begin{tabular}{lccc}
\hline Tipo de estaca & \multicolumn{3}{c}{ Peso da matéria seca das brotações (g) } \\
\cline { 2 - 4 } & 0 & \multicolumn{1}{c}{ Ácido indolbutírico $\left(\mathrm{mg} \mathrm{L}^{-1}\right)$} \\
\hline Sem folha & $16,25 \mathrm{aA}$ & 150 & 300 \\
Com folha & $19,68 \mathrm{aA}$ & $21,26 \mathrm{aA}$ & $16,14 \mathrm{aA}$ \\
& & $7,60 \mathrm{bB}$ & $\mathrm{bB}$ \\
\hline & & & 300 \\
\hline & 0 & Ácido indolbutírico $\left(\mathrm{mg} \mathrm{L}^{-1}\right)$ & $14,78 \mathrm{aB}$ \\
\hline Sem fruto & $18,27 \mathrm{aAB}$ & $21,38 \mathrm{aA}$ & $6,28 \mathrm{bB}$ \\
\hline
\end{tabular}

Médias seguidas por letras distintas, minúsculas na vertical e maiúsculas na horizontal, diferem entre si pelo teste de Tukey a $5 \%$ de probabilidade.

TABELA 3 - Peso da matéria seca das raízes de estacas de figueira, com ou sem folhas, retiradas com ou sem frutos, tratadas com ácido indolbutírico.

\begin{tabular}{|c|c|c|c|}
\hline \multirow[t]{3}{*}{ Tipo de estaca } & \multicolumn{3}{|c|}{ Peso da matéria seca das raízes (g) } \\
\hline & \multicolumn{3}{|c|}{ Ácido indolbutírico $\left(\mathrm{mg} \mathrm{L}^{-1}\right)$} \\
\hline & 0 & 150 & 300 \\
\hline Sem folha & $4,20 \mathrm{aAB}$ & $5,73 \mathrm{aA}$ & $3,64 \mathrm{aB}$ \\
\hline \multirow[t]{3}{*}{ Com folha } & $5,65 \mathrm{aA}$ & $2,32 \mathrm{bB}$ & $1,29 \mathrm{bB}$ \\
\hline & \multicolumn{3}{|c|}{ Ácido indolbutírico $\left(\mathrm{mg} \mathrm{L}^{-1}\right)$} \\
\hline & 0 & 150 & 300 \\
\hline Sem fruto & $4,92 \mathrm{aAB}$ & $6,00 \mathrm{aA}$ & $3,74 \mathrm{aB}$ \\
\hline Com fruto & $4,93 \mathrm{aA}$ & $2,05 \mathrm{bB}$ & $1,20 \mathrm{bB}$ \\
\hline
\end{tabular}

Médias seguidas por letras distintas, minúsculas na vertical e maiúsculas na horizontal, diferem entre si pelo teste de Tukey a $5 \%$ de probabilidade.

Ciênc. agrotec., Lavras, v. 31, n. 3, p. 914-920, maio/jun., 2007 


\section{REFERÊNCIAS BIBLIOGRÁFICAS}

ALBUQUERQUE, T. C. S. de; ALBUQUERQUE, J. A. S. de. Influência do tipo de estaca e de alguns reguladores de crescimento no enraizamento e desenvolvimento de estacas de figueira (Ficus carica L.). In: CONGRESSO BRASILEIRO DE FRUTICULTURA, 6., 1981, Recife. Anais... Recife: UFPE, 1981. n. 3, p. 762-770.

ALMEIDA, M. M.; SILVEIRA, E. T. Tratos culturais na cultura da figueira no Sudoeste de Minas Gerais. Informe Agropecuário, Belo Horizonte, v. 18, n. 188, p. 27-33, 1997.

ANTUNES, L. E. C.; CHALFUN, N. N. J.; RAMOS, J. D.; PASQUAL, M.; VEIGA, R. D. Influência de diferentes períodos de estratificação, concentrações de ácido indolbutírico e substratos no enraizamento de estacas de figueira. Ciência e Agrotecnologia, Lavras, v. 20, n. 3, p. 307-314, 1996.

ARRUDA NETO, J. S. O figo começa na estaca. Correio Agropecuário, São Paulo, v. 11, n. 183, p. 9, 1971.

BOSE, T. K.; MANDAL, D. P. Mist propagation of tropical plants. Indian Horticulturae, Bangalore, v. 17, p. 25-26, 1972.

CABALLERO, J. M.; NAHLAWI, N. Influence of carbohydrates and washing with water on the rooting of the Gordal cultivar of the olive (Olea europaea L.). Anais Instituto Nacional de Investigaciones Agrarias, Serie Producción Vegetal, Madrid, v. 11, p. 219-230, 1979.

CHALFUN, N. N. J.; ABRAHÃO, E.; ALVARENGA, A. A.; REGINA, M. de A.; PIO, R. Poda e condução da figueira. Lavras: UFLA, 2002. 12 p. (Boletim de extensão, 104).

CHALFUN, N. N. J.; HOFFMANN, A. Propagação da figueira. Informe Agropecuário, Belo Horizonte, v. 18, n. 188, p. 9-13, 1997.

CRANE, J. C.; MALLAH, T. S. Varietal root and top regeneration of fig cuttings as influenced by the application of indolebutyric acid. Plant Physiology, Lancaster, v. 27, p. 309-319, 1952.

DAVIES, T. D. Influence of photosynthesis and carbohydrates on adventitious root formation by leafy cuttings. Dissertation Abstracts International, Ann Arbor, v. 43, n. 10, p. 3090-3091, 1983.

DEL-RIO, C.; CABALLERO, J. M. Effects of carbohydrate content on the seasonal rooting of vegetative and reproductive cuttings of olive. Journal of Horticultural Science, Ashford, v. 66, n. 3, p. 301-309, 1991.
DUNBERG, A.; HSIHAN, S.; SANDBERG, G. Auxin dynamics and the rooting of cuttings of Pinus sylvestris. Plant Physiology, Lancaster, v. 67, p. 5, 1981. Supplement.

FACHINELLO, J. C.; HOFFMANN, A.; NACHTIGAL, J. C.; KERSTEN, E.; FORTES, G. R. de L. Propagação de plantas frutíferas de clima temperado. 2. ed. Pelotas: UFPEL, 1995. 179 p.

FONTANAZZA, G.; RUGINI, E. Effect of leaves and buds removal on rooting ability of olive tree cuttings. Olea, Córdoba, v. 2, p. 9-28, 1977.

KERSTEN, E.; FACHINELLO, J. C. Efeito do ácido indolbutírico (IBA) na percentagem de estacas herbáceas enraizadas de figueira (Ficus carica L.), cultivar Roxo de Valinhos, em condição de nebulização. Revista Agros, Pelotas, v. 16, n. 3/4, p. 5-10, 1981.

NORBERTO, P. M. Efeitos da época de poda, cianamida hidrogenada, irrigação a ácido indolbutírico na colheita antecipada e enraizamento de estacas de figueira (Ficus carica L.). 1999. 89 p. Dissertação (Mestrado em Agronomia) - Universidade Federal de Lavras, Lavras, 1999.

NUNES, R. F. de M. Influência do ácido indolbutírico (AIB) no enraizamento de estacas semilenhosas de figueira (Ficus carica L.), cultivar Roxo-de-Valinhos, e videira (Vitis vinifera L.), cultivar Itália, em condição de nebulização. 1981. 99 f. Dissertação (Mestrado) Universidade Federal de Pelotas, Pelotas, 1981.

PINHEIRO, R. V. R.; OLIVEIRA, L. M. de. Influência do comprimento da estaca de figueira (Ficus carica L.) no seu "pegamento", enraizamento e desenvolvimento do sistema aéreo. Ceres, Viçosa, v. 20, n. 107, p. 35-43, 1973.

PIO, R. Ácido indolbutírico e sacarose no enraizamento de estacas apicais e desenvolvimento inicial da figueira (Ficus carica L.). 2002. 109 p. Dissertação (Mestrado em Agronomia) - Universidade Federal de Lavras, Lavras, 2002.

RALLO, L.; DEL-RIO, C. Effect of a $\mathrm{CO}_{2}$ enriched environment on the rooting ability and carbohydrate level of olive cuttings. Advances in Horticultural Science, New York, v. 4, n. 2, p. 129-130, 1990.

SILVA, C. R. de R. Produção de figueira. Informe Agropecuário, Belo Horizonte, v. 9, n. 102, p. 30, 1983. 
TAIZ, L.; ZEIGER, E. Plant physiology. 2. ed. Sunderland: Sinauer Associates, 1998. 792 p.
VÁLIO, I. F. M. Auxinas. In: FERRI, M. G. Fisiologia vegetal. São Paulo: EPU, 1986. v. 2, p. 39-72. 